\title{
Experimental Investigation of High-cycle Fatigue Behavior for Automobile Structural Steel Based on Stress-Number-of-cycles Curves
}

\author{
Tianjun Zhu, ${ }^{1,2}$ Hongyan Zheng, ${ }^{*}$ and Ruoyu Zhao ${ }^{3}$ \\ ${ }^{1}$ Department of Mechanical and Automotive Engineering, Zhaoqing University, \\ Zhaoqing Road, Zhaoqing 526061, China \\ ${ }^{2}$ College of Mechanical and Equipment Engineering, Hebei University of Engineering, \\ Guangming Road, Handan 056021, China \\ ${ }^{3}$ China Automotive Technology \& Research Center, Xianfeng Road, Tianjin 300300, China \\ (Received August 31, 2018; accepted October 30, 2018)
}

Keywords: stamping steel plate, fatigue limit, $S-N$ curve, fatigue simulation analysis

An experimental sensing system and performance analysis of the measurement of the highcycle fatigue properties of automobile structural steel are presented. Firstly, the yield strength and tensile strength of the automobile body stamping steel plate are determined through a static uniaxial tensile test. In accordance with the stress ratio $R=0.1$, the stress at all levels is determined, and the tensile strength test based on stress is carried out. Secondly, the fatigue data obtained using Goodman's and Gerber's empirical formulas are modified to eliminate the effect of average stress. The fatigue analysis software program LabMOTION is used to acquire the stress-number-of-cycles $(S-N)$ curves of the material under different failure probabilities, and the fatigue limit of the material is obtained as well. The experimental results indicate that this method can be used to obtain the real fatigue characteristics of materials and that the fatigue limit obtained through Gerber's empirical formula and the slope of the $S-N$ curve of a finite-life region is more accurate. In this study, we provide a reference for future automobile body fatigue simulation analysis, parts design, and general product quality.

\section{Introduction}

When a car is running, it will be affected by weather, air current, road condition, and other factors, and the car bodywork and parts are subjected to cyclic load disturbance. Over time, fatigue damage gradually turns into microcracks that gradually expand, eventually leading to material fatigue fracture, which causes the malfunction of automobile parts, or in some cases, major damage to the driver and passengers.

Fatigue testing and analysis is the preferred technique for fatigue data acquisition, data analysis, and test planning and practice. Many efforts have been made to study the comprehensive methods of determining the component load, performing the fatigue damage assessment of a product, and developing an accelerated fatigue life test plan for reliability.

*Corresponding author: e-mail: happy.adam2012@hotmail.com https://doi.org/10.18494/SAM.2019.2135 
Dal et al. proposed a multiaxial fatigue criterion that can describe out-of-phase loading and a nonlinear damage rule. ${ }^{(1)}$ Zhao et al. provided an understanding of non-inclusion-induced cracks in high-cycle fatigue and guidance for automotive steel fatigue design. ${ }^{(2)}$ Zanon et al. investigated the correlations between material properties altered by the laser cutting process and the behavior of automotive material subjected to high-cycle fatigue. ${ }^{(3)}$ Gao et al. studied the mutual and relative effects of inclusions and microstructures on the very high cycle fatigue behavior of automotive multiphase steels. ${ }^{(4)}$ Soncino proved that in the high-cycle regime, a decrease in fatigue strength with increased number of cycles still occurs. ${ }^{(5)}$ Wang et al. provided a full-field calorimetric method for evaluating microplasticity in the very high cycle fatigue regime. ${ }^{(6)}$ Robertson studied the low-cycle fatigue characteristics of commonly used high-strength steels in detail using the strain mode. ${ }^{(7)}$ High-cycle fatigue has a large number of load cycles and little plastic deformation during cyclic loading. In the course of vehicle driving, the load on the body parts is small and the service life is long, which is in line with the characteristics of high-cycle fatigue. After a large number of experiments, it has been proved that the stress-life relationship measured by the stress-based test method can describe the characteristics of high-cycle fatigue.

At present, in the stress-based fatigue test, the group method and lifting method can be used to test the stress-life relationship and fatigue strength of a material. To obtain the fatigue properties of the material of a car body, in this paper, we proposed a sensing test system, which can be used in vehicle body design, for the high-cycle fatigue of stamping steel. The cycle times at all levels of stress of samples, as well as the data of stress and fatigue life are obtained under this test system based on the use of stress, which are fitted to the stress-number-of-cycles $(S-N)$ curve of the material. The fatigue performance data obtained from the test can provide a real reference value for fatigue simulation analysis, fatigue life prediction, and durability design of vehicle body parts.

\section{Static Uniaxial Tensile Test}

To evaluate the fatigue performance of car steel by a stamping test, the material yield strength, tensile strength, and stress-strain curve must be obtained through a static tensile test. Then the transverse and longitudinal directions of fatigued steel plate specimens and cyclic load size must be determined using the data of mechanical properties. The material commonly used in automobile car body design is usually a thin plate, and the uniaxial tensile test should be in accordance with GB/T 228.1-2002 (Metal Tensile Test, Part one: Room temperature test method) ${ }^{(8)}$ to process the stamping plate and to prepare a rectangular specimen. It is necessary to make a smooth connection between the working part of a specimen and the clamping part of a clamp, to ensure that there is no obvious defect in the arc transition part, and to determine the shape and size of the tensile test specimen in line with existing extensometer parameters, as shown in Fig. 1.

The equipment used for the uniaxial tensile test is the servo hydraulic control test system made by MTS Landmark, U.S.A (extensometer parameters: model 634.11F-24, range of 25 $\mathrm{mm}$, measurement range of +5 to $-2.5 \mathrm{~mm}$ ). In the proposed system, MTS Landmark sensing 


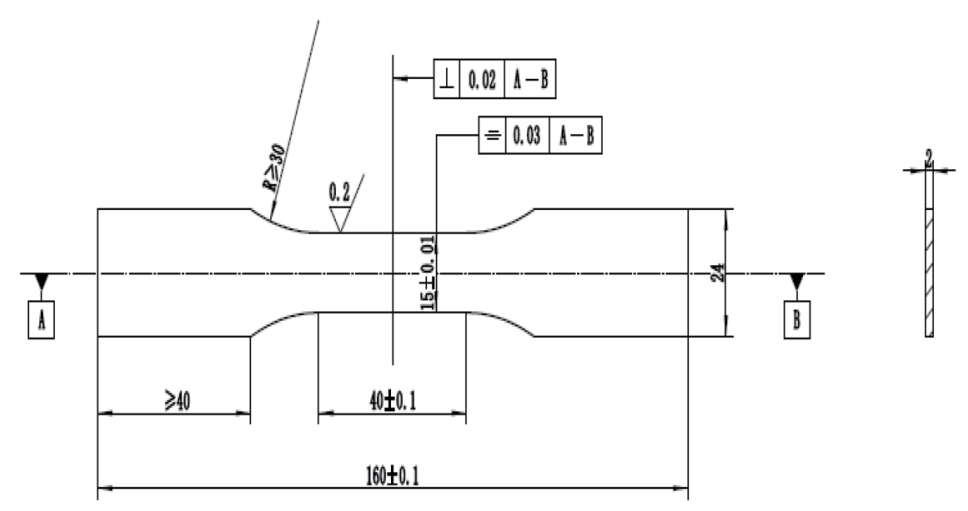

Fig. 1. Drawing of processing specimens.

systems are ideal for the exacting demands of material fatigue testing. Highly stiff integrated actuator beams, hydraulic grips, high-resolution force sensors, and precision alignment fixtures combine to deliver tightly controlled and consistent through-zero specimen loading. Moreover, the actuator force ratings range from 15 to $500 \mathrm{kN}$.

The advantage of using the wire-electrode cutting process for sample preparation and processing is that it can improve the efficiency of material utilization and reduce the amount of machining residual scrap. Moreover, the area of the sample affected by wire cutting of the sample is relatively small, whereby the risk of affecting the mechanical properties of the sample owing to excessive residual stress on the sample can be avoided. The cooling conditions should be good enough to prevent heat accumulation in the sample, as heat may change the fatigue properties of materials. When the sample is ready, it must be properly preserved.

During the preparation of the unidirectional tensile test, the test samples should be numbered. The stamping steel plate used in this paper is numbered 6 , and the state in the testing process and at the end of the test are shown in Fig. 2. Figure 3 shows the laboratory equipment used in the test.

In Fig. 2, sample 6\#-1-2-3 is taken as an example to explain the meaning of the specimen number in Table 1: 6 indicates the material number, 1 indicates the plate number, 2 indicates the direction of sampling (lateral and vertical), and 3 indicates the number of different samples under the same sampling direction. The mechanical properties obtained from the uniaxial tensile test are shown in Table 1.

According to the tensile test data, we should select the conservative lower limit value of yield strength and tensile strength of the material. Thus, we determined that the direction of fatigue test sampling should be direction 1, which represents the transverse direction of the material stamping process. The yield strength mean should be $275.5 \mathrm{MPa}$, and the mean tensile strength should be 453.3 MPa. The stress-strain curve of sample 6\#-1-1-3 is shown in Fig. 4.

\section{High-cycle Fatigue Test}

When the fatigue occurs above $10^{4}$ cycles (usually $10^{6}$ or more), it is usually called highcycle fatigue. The material is subjected to lower loads, usually less than $2 / 3$ of the yield stress 


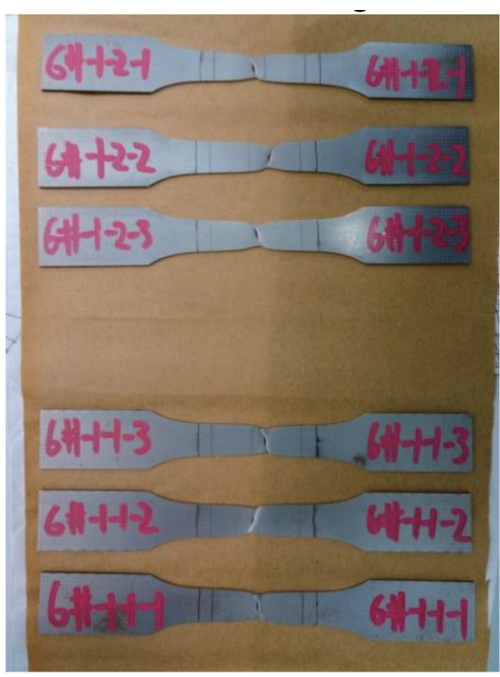

Fig. 2. (Color online) Specimens used in unidirectional tensile test.

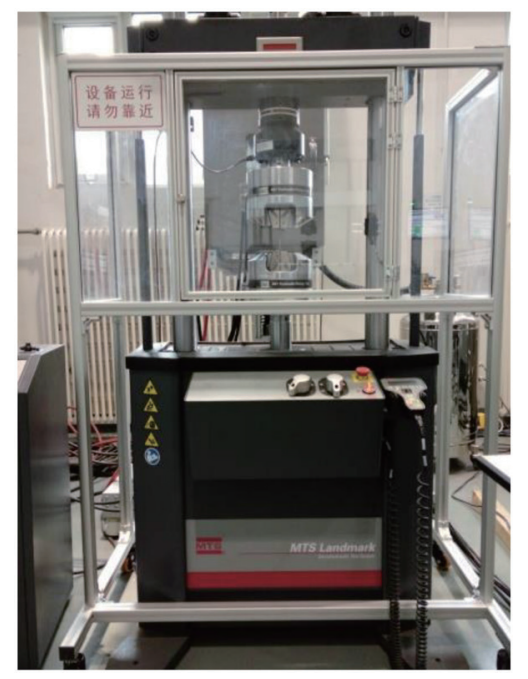

Fig. 3. (Color online) Scheme of laboratory equipment.

Table 1

Mechanical properties of plate No. 6 .

\begin{tabular}{lrccc}
\hline Specimen number & Yield strength $(\mathrm{MPa})$ & Mean value $(\mathrm{MPa})$ & Tensile strength $(\mathrm{MPa})$ & Mean value (MPa) \\
\hline 6\#-1-1-1 & 273.917 & & 451.853 & \\
6\#-1-1-2 & 276.497 & 275.459 & 455.092 & 453.302 \\
6\#-1-1-3 & 275.962 & & 452.960 & \\
\hline 6\#-1-2-1 & 298.104 & & 453.863 & \\
6\#-1-2-2 & 297.729 & 298.274 & 454.155 & 454.353 \\
6\#-1-2-3 & 298.988 & & 455.041 &
\end{tabular}

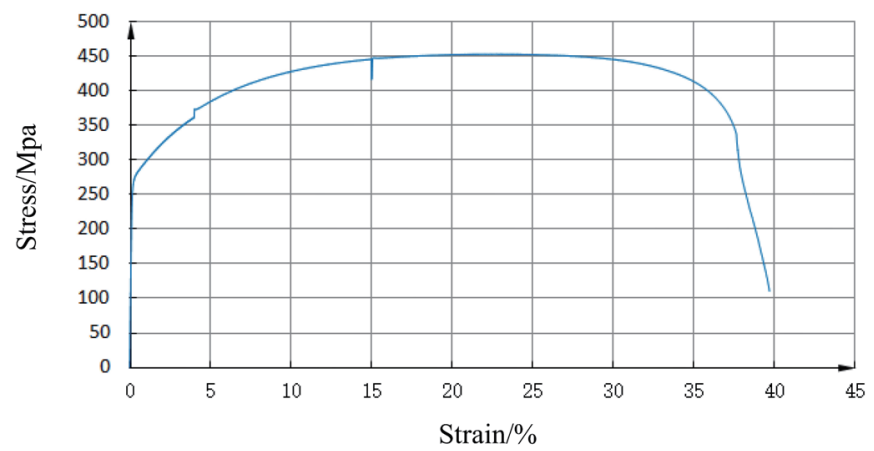

Fig. 4. (Color online) Stress-strain curve of sample.

during the high-cycle fatigue test. The deformation is in the elastic range. The flow chart of the high-cycle fatigue test in this study is shown in Fig. 5.

The machining dimensions recommended in the GB/T 26076-2010, Metal Sheets and StripsAxial-force-controlled Fatigue Testing Method $^{(9)}$ for circular arc specimens that undergo the high-cycle fatigue test for a metal sheet (belt) are shown in Fig. 6. 


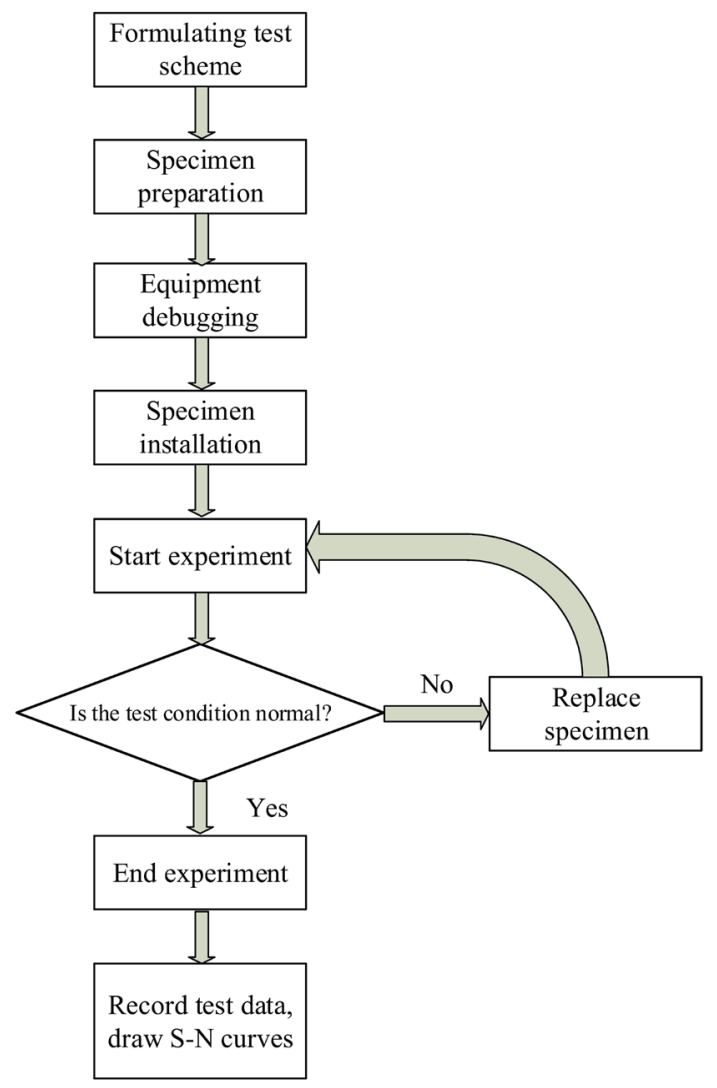

Fig. 5. (Color online) Flow chart of high-cycle fatigue test.

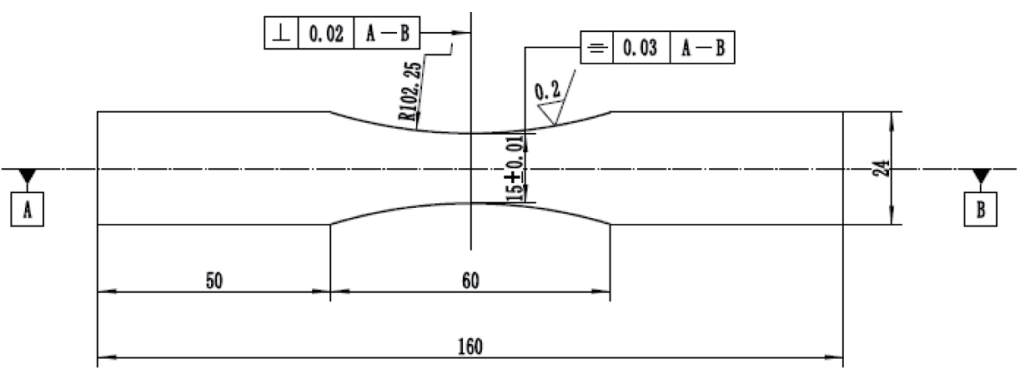

Fig. 6. High-cycle fatigue specimen.

After the sample is processed, it will be numbered at all stress levels in accordance with the test. After the numbering is finished, the sample will be installed on the equipment. As shown in Fig. 7, when the sample is installed, the specimen must be kept coaxial with the upper and lower fixtures of the tester.

The sample used in this test is a thin plate. Because the specimen is very thin, the tension and compression test can easily cause bending failure of the specimen if the test starts right after the symmetrical cyclic stress is loaded. Therefore, we use the stretch-stretch loading method and the stress ratio $R$ of 0.1 . When determining the stress at all levels, the fatigue strength of 


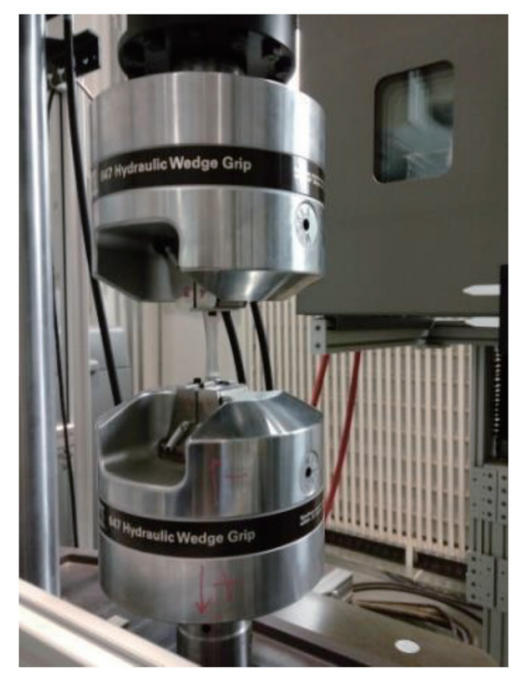

Fig. 7. (Color online) Installation of fatigue test specimens.

materials needs to be estimated. A variety of prediction methods can be used to estimate the fatigue strength, including making use of the multiple relationships between the tensile and fatigue strengths, ${ }^{(10)}$ and using the relationship formula between the fatigue strength and the yield strength for prediction. ${ }^{(11)}$ Some researchers obtain the fatigue strength using the fitting $S-N$ curve equation based on fatigue life data, which is collected through fatigue tests under different stress levels, and then the number of cycles to reach the $10^{7}$ stress level is obtained to estimate the fatigue strength. ${ }^{(12)}$ In addition, the fatigue strength can be obtained through Eq. (1), which is used to estimate the fatigue strength limit; the estimated stress ratio $R$ in this case is -1 . Then, it is modified into the maximum stress value when $R=0.1$ through an empirical formula, and an exploratory experiment is carried out in the vicinity of the estimated value; this method has higher reliability.

$$
S_{a}=0.45 S_{u} C_{L} C_{S} C_{D} C_{R}
$$

In the formula, $S_{a}$ is the stress amplitude corresponding to $10^{7}$ cycles, $S_{u}$ is the tensile strength, $C_{L}$ is the correction coefficient of loading type, $C_{S}$ is the surface mass coefficient and is $0.98, C_{D}$ is the size coefficient, and $C_{R}$ is the reliability level coefficient. Here, $S_{u}$ is $453.3 \mathrm{MPa}, C_{L}$ is axial loading and is $0.9, C_{S}$ is $0.98, C_{D}$ is 1 , and $C_{R}$ is 1 . The test stress levels determined are shown in Table 2.

The fatigue test of the sample is carried out with the determined stress level. The number of test subjects at each stress level is 4 . Considering the possible errors and accidents in the test, one or two samples will be tested at a certain stress level. The experimental data obtained in the experiment are shown in Table 3.

To shorten the test period and cost, a simple exploratory test was carried out with stress amplitudes of 186 and $190 \mathrm{MPa}$, and it was found that the number of cycles reached $10^{7}$ without breakage of the sample. In the following test, if the stress amplitude increases owing 
Table 2

Stress levels in all tests.

\begin{tabular}{lcccc}
\hline $\begin{array}{l}\text { Stress amplitude } \\
(\mathrm{MPa})\end{array}$ & Stress ratio & $\begin{array}{c}\text { Maximum stress } \\
(\mathrm{MPa})\end{array}$ & $\begin{array}{c}\text { Minimum stress } \\
(\mathrm{Mpa})\end{array}$ & $\begin{array}{c}\text { Average stress } \\
(\mathrm{Mpa})\end{array}$ \\
\hline 200 & 0.1 & 444.44 & 44.44 & 244.44 \\
198 & 0.1 & 440.00 & 44.00 & 242.00 \\
196 & 0.1 & 435.56 & 43.56 & 239.56 \\
194 & 0.1 & 431.11 & 43.11 & 237.11 \\
192 & 0.1 & 426.67 & 42.67 & 234.67 \\
190 & 0.1 & 422.22 & 42.22 & 232.22 \\
186 & 0.1 & 413.33 & 41.33 & 227.33 \\
\hline
\end{tabular}

Table 3

Number of cycles in stress level test.

\begin{tabular}{|c|c|c|c|c|c|}
\hline $\begin{array}{l}\text { Specimen } \\
\text { number }\end{array}$ & $\begin{array}{l}\text { Stress amplitude } \\
\text { (MPa) }\end{array}$ & Number of cycles & $\begin{array}{l}\text { Specimen } \\
\text { number }\end{array}$ & $\begin{array}{l}\text { Stress amplitude } \\
\text { (MPa) }\end{array}$ & Number of cycles \\
\hline 6\#-T-1 & 186 & 10000021 & $6 \#-C-2$ & 196 & 10000028 \\
\hline $6 \#-T-2$ & 190 & 10000024 & $6 \#-C-3$ & 196 & 10000023 \\
\hline 6\#-T-3 & 190 & 10000024 & $6 \#-C-4$ & 196 & 1001275 \\
\hline $6 \#-A-1$ & 192 & $\begin{array}{c}1652588 \\
\text { (Clamping end failure) }\end{array}$ & $6 \#-C-5$ & 196 & 348719 \\
\hline $6 \#-A-2$ & 192 & 10000021 & $6 \#-C-6$ & 196 & 986564 \\
\hline $6 \#-A-3$ & 192 & $\begin{array}{c}1520022 \\
\text { (Clamping end failure) }\end{array}$ & 6\#-D-1 & 198 & 336050 \\
\hline $6 \#-A-4$ & 192 & 10000024 & $6 \#-D-2$ & 198 & 181147 \\
\hline $6 \#-A-5$ & 192 & 2454212 & $6 \#-D-3$ & 198 & 1024702 \\
\hline $6 \#-A-6$ & 192 & 10000021 & $6 \#-D-4$ & 198 & 10000024 \\
\hline $6 \#-B-1$ & 194 & 10000021 & $6 \#-D-5$ & 198 & 548913 \\
\hline $6 \#-B-2$ & 194 & 869828 & $6 \#-E-1$ & 200 & 4559 \\
\hline $6 \#-B-3$ & 194 & 957065 & $6 \#-E-2$ & 200 & 26097 \\
\hline $6 \#-B-4$ & 194 & $\begin{array}{c}1536629 \\
\text { (Clamping end failure) }\end{array}$ & $6 \#-E-3$ & 200 & 19377 \\
\hline $6 \#-B-5$ & 194 & 681865 & $6 \#-E-4$ & 200 & $\begin{array}{c}1052155 \\
\text { (Clamping end failure) }\end{array}$ \\
\hline $6 \#-C-1$ & 196 & 116656 & 6\#-E-5 & 200 & 10000000 \\
\hline
\end{tabular}

to inaccurate operation, the sample installation becomes imprecise, resulting in some samples showing clamping-end failure, and thus, the data is invalid. The cycle times of sample 6\#-A-5 cycles at the same stress level are rather small compared with those of other samples at the same stress level; this is because the surface has obvious pits and defects that lead to quick cracking. The number of cycles of some samples at the same stress level varies greatly; even under a high stress level, it may reach $10^{7}$ without the occurrence of fatigue failure. The data is considered invalid in this case.

\section{Processing of Test Data}

Usually, the basic $S-N$ curve of the material refers to the $S-N$ curve when the stress ratio $R$ is -1 and the average stress $S_{m}$ is 0 . The mean stress has a considerable effect on the actual material fatigue life. The average stress effect of $S_{m}$ on the basic $S-N$ curve is shown in Fig. 8, where you can see that when $S_{m}>0$, the basic $S-N$ curve drops, which has a negative impact on the fatigue properties of materials. When $S_{m}<0$, the basic $S-N$ curve shifts upward, and the 
fatigue performance is reinforced. ${ }^{(13)}$ In practice, the average stress affects the fatigue life of materials considerably. In Fig. 8, the average stress is tensile average stress when $S_{m}>0$, and it will reduce the fatigue life of materials. At the same time, the average stress is compressive average stress when $S_{m}<0$, and it will increase the fatigue life of materials. Therefore, in practical engineering, cold extrusion, shot blasting, prestrain, and other methods are used to introduce residual compressive stress so as to improve the fatigue life. To eliminate the effect of average stress on fatigue life, two empirical formulas of Goodman and Gerber were used to correct the mean stress, and the fatigue limit $S_{-1}$ at the stress ratio $R$ of -1 is obtained.

Goodman's correction equation is

$$
S_{e}=\frac{S_{a}}{1-\frac{S_{m}}{S_{b}}} .
$$

Gerber's correction equation is

$$
S_{e}=\frac{S_{a}}{1-\left(\frac{S_{m}}{S_{b}}\right)^{2}} .
$$

In the formulas, $S_{e}$ is the stress amplitude when the stress ratio is -1 and the average stress is $0 . S_{a}$ is the stress amplitude when the stress ratio is not -1 and the average stress is not $0 . S_{m}$ is the average stress when the stress ratio is not -1 and is not $0 . S_{b}$ is the tensile strength of the material.

Owing to the small plastic deformation of the sample during the test, the minimum section area decreases and the actual stress level increases. The minimum section area of the sample is measured when the test is stable or at the end of the test, so as to obtain the actual stress level. The amplitude of the stress listed in Table 4 is used in the correction.

The fatigue limit $S_{-1}$, when the stress ratio $R$ of material No. 6 is -1 , is calculated using the two empirical formulas and shown in Table 5.

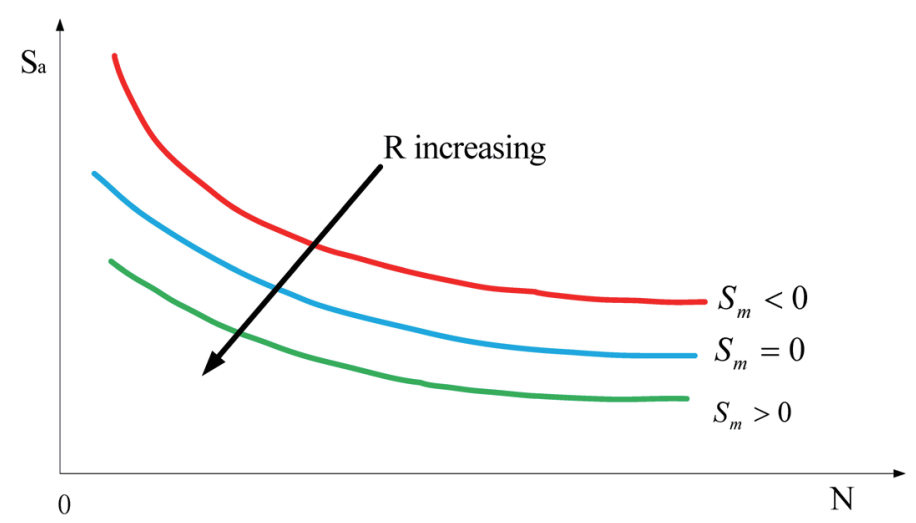

Fig. 8. (Color online) Effects of average stress. 
Table 4

Measured and calculated stress amplitudes.

\begin{tabular}{lllllll}
\hline Setting stress amplitude $S_{a}(\mathrm{MPa})$ & 186 & 192 & 194 & 196 & 198 & 200 \\
\hline $\begin{array}{l}\text { Measured and calculated stress } \\
\text { amplitude } S_{a}(\mathrm{MPa})\end{array}$ & 199 & 212 & 216 & 222 & 226 & 232 \\
\hline
\end{tabular}

Table 5

Stress amplitude after correction.

\begin{tabular}{|c|c|c|c|c|c|}
\hline $\begin{array}{l}\text { Setting stress } \\
\text { amplitude } \\
S_{a}(\mathrm{MPa})\end{array}$ & $\begin{array}{c}\text { Measured and } \\
\text { calculated stress } \\
\text { amplitude } S_{a}(\mathrm{MPa})\end{array}$ & $\begin{array}{l}\text { Average stress } \\
\quad S_{m}(\mathrm{Mpa})\end{array}$ & $\begin{array}{l}\text { Ultimate tensile } \\
\text { strength } S_{u}(\mathrm{MPa})\end{array}$ & $\begin{array}{c}\text { Fatigue limit } \\
S_{-1}(\mathrm{MPa}) \\
\text { (Goodman) }\end{array}$ & $\begin{array}{c}\text { Fatigue limit } \\
S_{-1}(\mathrm{MPa}) \\
\text { (Gerber) }\end{array}$ \\
\hline 200 & 232 & 283.56 & 453 & 620.24 & 381.46 \\
\hline 198 & 226 & 276.22 & 453 & 579.13 & 359.76 \\
\hline 196 & 222 & 271.33 & 453 & 553.57 & 346.21 \\
\hline 194 & 216 & 264.00 & 453 & 517.71 & 327.09 \\
\hline 192 & 212 & 259.11 & 453 & 495.31 & 315.09 \\
\hline 190 & 210 & 256.67 & 453 & 484.53 & 309.29 \\
\hline 186 & 199 & 243.22 & 453 & 429.73 & 279.60 \\
\hline
\end{tabular}

The stress amplitude is corrected using two empirical formulas, Goodman's formula and Gerber's formula, and the $P-S-N$ curves under different failure probabilities $(P a=90,50$, and 10) are obtained using the fatigue analysis software program LabMOTION. $P-S-N$ curves indicate SN curves corresponding to different failure probabilities $(P)$ and the dispersion of fatigue life. They are shown in Figs. 9 and 10, respectively. The data points with parentheses in the figure are selected as invalid points.

As can be seen from the above figures, the relationship between stress and the number of cycles can be expressed as a straight line, and the least-squares method is used to fit the data of the finite-life region. Before the fitting, the regression model and the regression line equation $^{(14,15)}$ are determined as Eqs. (4) and (5).

$$
Y=A+B X+\varepsilon
$$

Here, $\varepsilon$ is a random error variable.

$$
Y=\bar{A}+\bar{B} X
$$

Here, $\bar{A}$ and $\bar{B}$ are the values estimated by minimizing the sum of the squares of the $Y$ deviations using

$$
\begin{gathered}
\bar{A}=\bar{Y}-\bar{B} \bar{X}, \\
\bar{B}=\frac{\sum_{i=1}^{n_{s}}\left(X_{i}-\bar{X}\right)\left(Y_{i}-\bar{Y}\right)}{\sum_{i=1}^{n_{s}}\left(X_{i}-\bar{X}\right)^{2}} .
\end{gathered}
$$




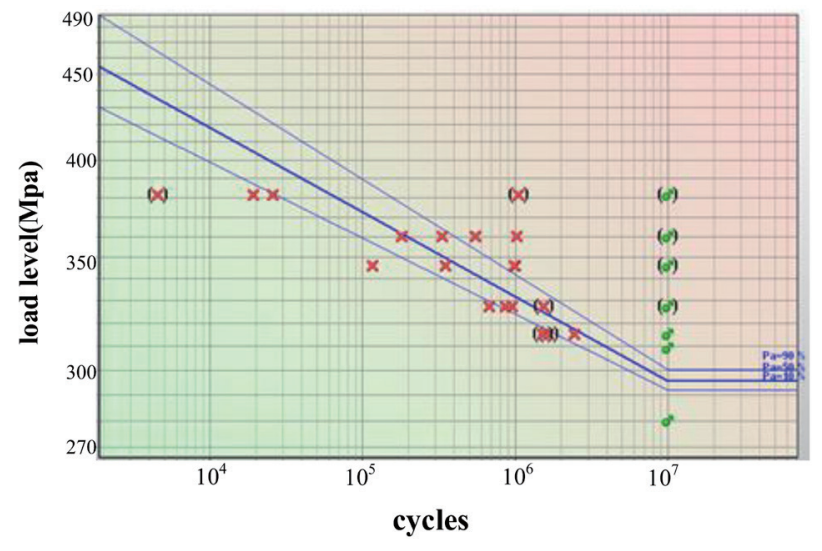

Fig. 9. (Color online) $P-S-N$ curves under different failure probabilities after Goodman's correction.

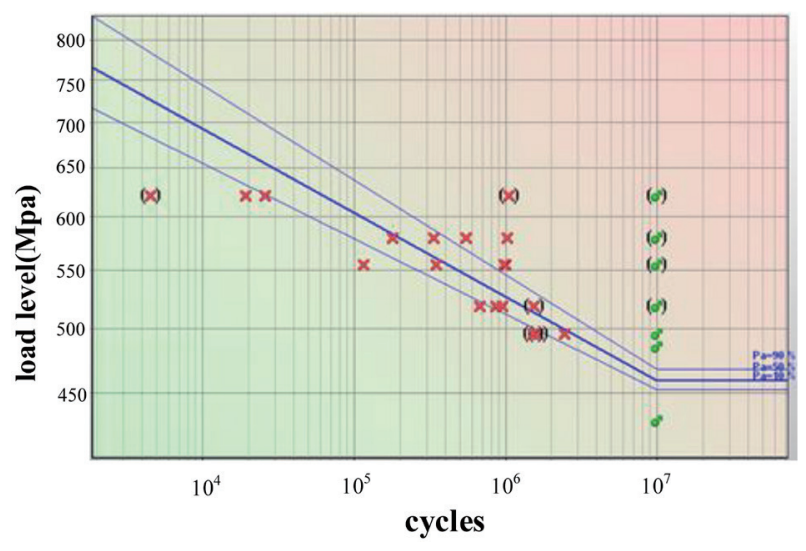

Fig. 10. (Color online) $P-S-N$ curves under different failure probabilities after Gerber's correction.

Here, $\bar{X}$ and $\bar{Y}$ are the average values.

Taking the logarithm of the two sides of the equation $S_{a}=\left(S_{f}^{\prime} \times 2^{b}\right)\left(N_{f}\right)^{b}$, which describes the $S-N$ curve, we obtain

$$
\lg \left(N_{f}\right)=-\frac{1}{b} \lg \left(S_{f}^{\prime} \times 2^{b}\right)+\frac{1}{b} \lg \left(S_{a}\right) .
$$

Compared with the regression line equation, it is easy to see the independent variable $X=$ $\lg \left(S_{a}\right)$, the strain $Y=\lg \left(N_{f}\right)$, the coefficient $\bar{A}=-\frac{1}{b} \lg \left(S_{f}^{\prime} \times 2^{b}\right)$, and the coefficient $\bar{B}=\frac{1}{b}$. The formula of the fatigue strength coefficient $S_{f}^{\prime}$ and the fatigue strength index $b$ can be obtained, as shown in Eqs. (9) and (10).

$$
\begin{gathered}
b=\frac{1}{\bar{B}} \\
S_{f}^{\prime}=\frac{10(-\bar{A} b)}{2^{b}}
\end{gathered}
$$

It can be seen that the fatigue strength coefficient $S_{f}^{\prime}$ determines the intercept on the ordinate of the $S-N$ curve, whereas the fatigue strength index $b$ determines the slope of the straight line in the limited life area of the $S-N$ curve.

The fatigue limit strength and the slope of the straight line in the double logarithmic coordinate system calculated using the fatigue analysis software program LabMOTION under different failure probabilities are summarized in Table 6 .

To ensure the conservative limit of fatigue properties for an automobile body stamping plate, the use of Gerber's empirical formula is proposed to make the stress correction and to eliminate the effect of the average stress. 
Table 6

Fatigue limit and line slope under different failure probabilities.

\begin{tabular}{lcccc}
\hline Failure & \multicolumn{2}{c}{ Goodman } & \multicolumn{2}{c}{ Gerber } \\
\cline { 2 - 5 } $\begin{array}{l}\text { probability } \\
(\%)\end{array}$ & $\begin{array}{c}\text { Fatigue limit } \\
S_{-1}(\mathrm{MPa})\end{array}$ & Slope of line & $\begin{array}{c}\text { Fatigue limit } \\
S_{-1}(\mathrm{MPa})\end{array}$ & Slope of line \\
\hline 10 & 452 & -0.0536 & 292 & -0.0452 \\
50 & 459 & -0.0596 & 296 & -0.0502 \\
90 & 467 & -0.0671 & 300 & -0.0566 \\
\hline
\end{tabular}

\section{Conclusions}

In this study, we proposed an experimental sensing system for the measurement of the highcycle fatigue properties of automobile structural steel. The proposed system makes use of Goodman's and Gerber's empirical formulas, and the ease of eliminating the effect of average stress is highly satisfactory. The proposed system is also used to acquire the $S-N$ curves of the material under different failure probabilities. Hence, the proposed method can be used to analyze and conduct the fatigue simulation of vehicle body parts in the future, so as to improve product quality and provide an important reference for improving the reliability of vehicles.

\section{Acknowledgments}

The authors would like to acknowledge the financial support of the Collaborative Innovation and Platform Environment Construction Project of Guangdong Province (2015A050502053) and the High Level Talents Foundation of Hebei Province (A2016002025) and Hebei Province Key R \& D Project (17394501D). The authors would also like to acknowledge the financial support of the Natural Science Foundation of Characteristic Innovation Project of Guangdong Ordinary University and Science and Technology Research Project of Hebei Higher Education (ZD2017213). The authors also acknowledge the financial support of subsidized projects for overseas students (CL201705).

\section{References}

1 F. Dal, Q. H. Vu, D. Halm, and Y. Nadot: Int. J. Fatigue 117 (2018) 461. https://doi.org/10.1016/ j.ijfatigue.2018.08.013

2 P. Zhao, Z. Liu, R. D. K. Misra, F. Du, C. Zhang, Z. G. Yang, and E. Yan: Mater. Sci. Eng., A 712 (2018) 406. https://doi.org/10.1016/j.msea.2017.11.119

3 G. Zanon, O. S. Bursi, P. Scardi, M. D’Incau, and S. Raso: Constr. Build. Tech. 12 (2018) 83. https://doi. org/10.2174/1874836801812010083

4 G. H. Gao, Q. Z. Xu, H. R. Gao, X. L. Cui, B. X. Zhang, and B. Z. Bai: Mater. Sci. Eng., A 714 (2018) 73. https://doi.org/10.1016/j.msea.2018.10.073

5 C. M. Soncino: Int. J. Fatigue 29 (2007) 2246. https://doi.org/10.1016/j.ijfatigue.2006.11.015

6 X. G. Wang, E. S. Feng, and C. A. Jiang: Int. J. Fatigue 94 (2016) 6. https://doi.org/10.1016/j.ijfatigue.2016.09.004

7 L. Robertson: Ph.D. Thesis, Deakin University (2011).

8 Metallic Materials-Tensile Testing at Ambient Temperature: Chinese Stand GB/T228-2002 (2002).

9 Metal Sheets and Strips-Axial-Force-Controlled Fatigue Testing Method: Chinese Stand GB/T26076-2010 (2011).

10 W. X. Yao: Fatigue Life Prediction of Structures (National Defense Industry Press, Berlin, Heidelberg, 2004) p. 112. 
11 M. Wang: Principle \& Technology of Anti-Fatigue Manufacture (Guangming Daily Press, Beijing, 2011) p. 56.

12 C. L. Chen: Fatigue and Fracture (Huazhong University of Science and Technology Press, Wuhan, 2011) p. 32.

13 C. H. Zeng and Y. S. Wu: Acta Mech. Solida Sin. 1 (1982) 71. https://doi.org/10.19636/j.cnki.cjsm42-1250/ 03.1982.01.008

14 W. Z. Gerber: Bayer. Arch. Eng. 6 (1874) 71. https://www.researchgate.net/publication/284378288

15 J. Goodman: Mechanics Applied to Engineering (Longmans Press, London, 1919) p. 631.

\section{About the Authors}

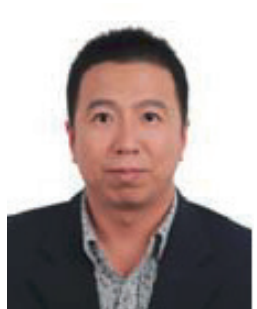

Tianjun Zhu received his B.S. degree from Hebei Agricultural University, China, in 2000 and his M.S. and Ph.D. degrees from Jilin University, China, in 2005 and 2010, respectively. From 2011 to 2016, he was an associate professor at Hebei University of Engineering, China. Since 2017, he has been a professor at Zhaoqing University. His research interests are in vehicle dynamic control, measurement, and sensors. (zhutianjun@zqu.edu.cn)

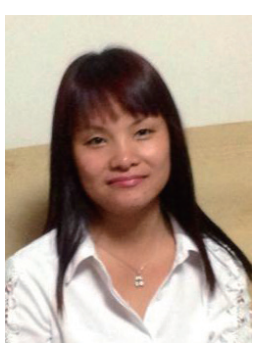

Hongyan Zheng received her B.S. degree from Hebei University, China, in 2000 and her M.S. degree from Hebei Normal University, China, in 2007. Since 2011, she has been an associate professor at Zhaoqing University, China. Her research interests are in mechanical engineering, measurement, and sensors. (happy.adam2012@hotmail.com)

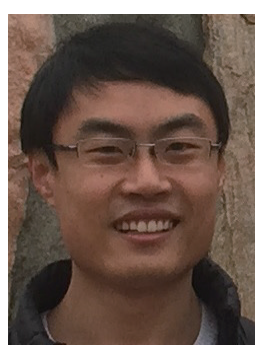

Ruoyu Zhao received his B.S. and M.S. degrees from Hebei University of Engineering, China in 2014 and 2017, respectively. Since 2017, he has been an engineer at the China Automotive Technology \& Research Center. His research interests are in mechanical engineering, measurement, and sensors. (zhaoruoyu@catarc.ac.cn) 